\title{
Development of Psychomotor Domain Assessment Instrument on Brake System Competence in SMKN 1 Jetis Mojokerto
}

\author{
Sudirman Rizki Ariyanto $1, a^{*}$, Munoto $1, \mathrm{~b}$, Muhaji ${ }^{2, c}$ \\ ${ }^{1}$ Technology and Vocational Education, Postgraduate, Universitas Negeri Surabaya, East Java, 60213, Indonesia \\ 2Department of Mechanical Engineering, Faculty of Engineering, Universitas Negeri Surabaya, East Java, 60213, 1Indonesia \\ a sudirman.17070895007@mhs.unesa.ac.id; b munoto@unesa.ac.id; c muhaji61@unesa.ac.id \\ ${ }^{*}$ Corresponding Author \\ Whatsapp number: [085707100057]
}

How to Cite : Ariyanto, S., R., Munoto, M., Muhaji, M. (2019). Development of Psychomotor Domain Assessment Instrument on Brake System Competence in SMKN 1 Jetis Mojokerto. International Journal for Educational and Vocational Studies, 1 (6), 585-590

\section{ARTICLE HISTORY}

Received: 2 August 2019

Revised: 27 August2019

Accepted: 27 September 2019

\section{KEYWORDS}

Vocational High School;

Psychomotor Domain Assessment; ADDIE Model;

Brake System Competence;

\section{ABSTRACT}

Many factors influence the low number of skilled vocational high school graduates. One factor that is the leading cause is the lack of instruments that can be used in the learning process, especially authentic instruments, to assess students' abilities in the psychomotor domain. Students who are dominant in the cognitive sphere are not necessarily skilled in the psychomotor realm, especially when using the equipment and making improvements to the brake system. The purpose of this study is to develop an assessment instrument that is appropriate to beused by the teacher in evaluating the psychomotor domain's abilities, specifically for the brake system competency. This research is development research that uses ADDIE models as a reference for research. ADDIE model has five stages of development that need to be considered, including analysis; (2) design; (3) development; (4) implementations; and (5) evaluation. Based on the results of the analysis and discussion of the psychomotor domain assessment instrument for the competency of the brake system that was developed to be suitable for use in the learning process. Feasibility is proven from the results of the validation of experts who get an assessment of 4.66 with a very valid category. The instrument reliability test results that get the Cronbach's alpha value of 0.895 , and the value of inter-observer reliability is 0.740 . In addition, the instrument is also practical when used in the learning process. This was evidenced by the acquisition of practicality test value of 3.31 and entered in the practical category.

This is an open access article under the CC-BY-SA license.

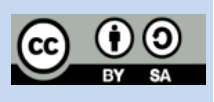

\section{INTRODUCTION}

Assessment is one way that is used by teachers in measuring the achievement of student learning. The assessment focuses more on numerical assessment and has a smaller scope when compared to evaluation. In this case, as we know, the evaluation process can be carried out after the teacher has carried out the stages of assessment of the learning process of students in the class (Lekwa, Reddy, Dudek, \& Hua, 2019).

Generally, the reference used in conducting the assessment process is the taxonomy of bloom. In theory, it is stated that the assessment of the learning process includes the cognitive, affective, and psychomotor domains (Kasilingam, Ramalingam, \& Chinnavan, 2014). The cognitive domain is assessed to assess student knowledge. Affective domains are used to assess student attitudes during the learning process (Ariyanto, Munoto, \& Muhaji, 2019). While the psychomotor domain is used to assess students' skills, this study will focus on the assessment of the psychomotor domain of students, especially on the competency of the brake system.

The psychomotor domain is one of the assessments that must be carried out by the teacher in addition to assessing the cognitive and affective domains. The psychomotor domain assessment will be easier for the teacher to do when students carry out the brake system practicum in the school workshop (Begam \& Tholappan, 2018). The goal is so that the teacher can do an authentic assessment based on the skills shown by students during the practical process. Students who are dominant in the cognitive realm are not necessarily skilled in the psychomotor realm, especially when using the equipment and making improvements to the brake system.

Assessment of students' skills when practicing the brake system is called the psychomotor skills assessment, which is assessed by the teacher as an observer. The 
assessment process will be easier if assisted by the existence of an instrument that supports the assessment of the psychomotor domain of students. The tool is very much needed because it can facilitate the teacher in measuring students' psychomotor skills authentically. From the results of observations and interviews conducted with the teaching teacher, it is known that during this time, the assessment was carried out using instruments that were still general. While the psychomotor realm instruments that are specific and authentic even do not yet exist.

Based on the analysis of these needs, the objectives of this study include: (1) analyzing the validity of psychomotor assessment instruments developed based on expert validation; (2) analyze the reliability of psychomotor assessment instruments developed based on the results of the trial; and (3) analyze the practicality of psychomotor assessment instruments developed based on the results of the test.

\section{METHODS}

In this development research the model used was the ADDIE model. There are five stages that need to be considered namely analysis; design; development; implementations; and evaluation (Branch, 2009). The subject of this study included students of class XI TKRO 1 in SMKN 1 Jetis Mojokerto with 34 students and three expert validators in the field of automotive engineering.

\subsection{Analysis Phase}

In this phase, the analysis is carried out through observational studies, interviews, and documentation. Observation and interview studies were conducted on teachers who taught brake system competencies in Jetis 1 Jetis Mojokerto. From the results of observational and interview studies, it is known that the instruments that have been used to measure the psychomotor domain of students are still not maximized. The causes of these problems include (1) existing instruments that are still general or not specific to the ability to be achieved; (2) teachers experience difficulties in using available instruments; and (3) teachers have problem in composing the ideal instrument especially for automotive engineering competencies, due to the lack of references related to psychomotor domain capability instruments.

After the observation and interview steps of the study are complete, then proceed to the documentation study phase. At this step, several studies were conducted on the theory and relevant research results which can be used as references in assessing psychomotor domain capabilities (Ahmad, Kamin, \& Md.Nasir, 2018). Based on the results of the needs assessment, the solution offered is to develop an ideal assessment instrument to assess the psychomotor domain abilities of students, especially in the brake system competency.
In this study the data obtained were analyzed to find out (1) validity; (2) reliability; and (3) the practicality of the psychomotor domain assessment instrument on the competency of the brake system developed.

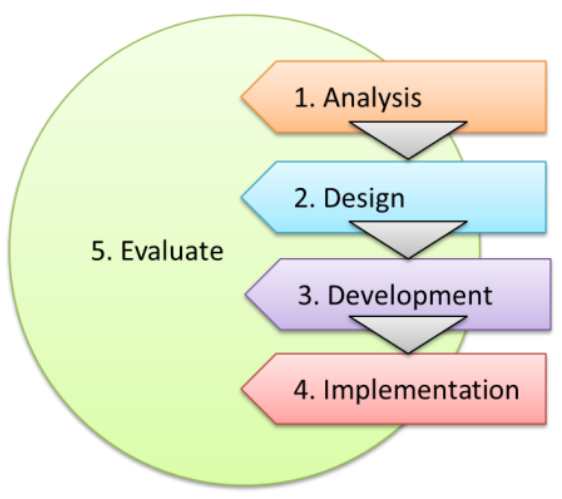

Figure 1. ADDIE Model Phase

Source: Hebebci, et al. (2014)

\section{RESULTS AND DISCUSSION}

\subsection{Results}

The results of this study obtained by each phase in the ADDIE models. The following are the stages and implementation of the ADDIE model when developing a psychomotor domain assessment instrument on the braking system competency.

\section{Design Phase}

The design phase is generally better known as the design or blueprint. In this study, which will be developed is a psychomotor domain assessment instrument for brake system competencies following the need assessment (Nahadi, Firman, \& Yulina, 2016). Therefore, designed in this instrument are assessment indicators that can measure students' psychomotor abilities from the beginning to the end of the brake system practicum process.

\section{Development Phase}

The development phase is the embodiment of the design or blueprint that has been designed before. In this study, the design that has been designed is manifested into a product in the form of an instrument. Procedures that need to be considered in this phase are (1) the initial product of the instrument is produced; (2) the initial product that has been completed will be validated by experts.

The instrument's initial product is the embodiment of the instrument that has been designed. In this step, psychomotor domain capability assessment instruments are arranged based on the concepts and designs that have been determined. After the instrument has been compiled, it is followed by designing an assessment rubric that can later be used to help facilitate the teacher in giving an assessment when making observations (Chowdhury, 2018). 
The next step is to test the validity of the instrument to experts. Validity testing is done to determine the level of reliability and feasibility of the instruments being developed. The results of the validity tests that have been carried out can be seen in Table 1 .

Table 1. Validation Results of the Psychomotor Domain Assessment Instrument on Brake System Competence

\begin{tabular}{llll}
\hline No. & Aspect & Value & Category \\
\hline 1 & Material & 4,62 & Very Valid \\
2 & Design & 4,62 & Very Valid \\
3 & $\begin{array}{l}\text { Language or } \\
\text { Culture }\end{array}$ & 4,74 & Very Valid \\
\hline \multicolumn{2}{l}{ Average } & 4,66 & Very Valid \\
\hline
\end{tabular}

Based on the data in Table 1, the results of the average validation of the three validators are 4.66 with very valid categories. The results of the validation show that the psychomotor domain assessment instrument on the braking system competency has conformity to every aspect of the assessment so that it can be concluded that the instrument is feasible when used to assess the psychomotor abilities of students, especially for the brake system competency.

\section{Implementation Phase}

In this phase, the psychomotor domain assessment instrument for the braking system competency was implemented in the actual conditions, namely in the XI TKRO 1 class at SMKN 1 Jetis Mojokerto. In the assessment process, there are at least three observers involved, there are one teacher and two colleagues. This phase is carried out to aim to test the reliability and practicality of the instruments being developed. The technique used to test reliability is the Cronbach's Alpha technique with the help of SPSS 24 software. The results of Cronbach's Alpha technique can be seen in Table 2 .

\begin{tabular}{|c|c|}
\hline \multicolumn{2}{|l|}{ Reliability Statistics } \\
\hline Cronbach's Alpha & $\mathrm{N}$ of Items \\
\hline 0,895 & 3 \\
\hline
\end{tabular}

Whereas the results of processing reliability data between observers were carried out using the Intraclass Correlation Coefficient (ICC) technique, where the reliability test results can be seen in Table 3 .

Table 3. Reliability Test Results for Psychomotor Domain Assessment Instruments for The Inter-Observer Brake System Competency

\begin{tabular}{lcll}
\hline Intraclass Correlation Coefficient & \multicolumn{2}{l}{ 95\% Confidence Interval } \\
\hline & $\begin{array}{l}\text { Intraclass } \\
\text { Correlationa }\end{array}$ & $\begin{array}{l}\text { Lower } \\
\text { Bound }\end{array}$ & Upper Bound \\
& & 0,537 & 0,886 \\
Single Measures & $0,746 \mathrm{~b}$ & 0,777 & 0,959 \\
Average Measures & $0,898 \mathrm{c}$ & & \\
\hline
\end{tabular}

After carrying out reliability tests, the next step is the practical level test. Practical tests are conducted to evaluate the practicality of the instrument when used to assess students' psychomotor abilities. The practicality test results can be seen in Table 4 .

Table 4. Practical Test Results for Psychomotor Domain Assessment Instruments for Brake System Competence

\begin{tabular}{lllllll}
\hline & Observer & & 3 & Average & Overall Average & Category \\
\cline { 2 - 3 } & 1 & 2 & 3 & 3,33 & \\
\hline 1 & 4 & 3 & 4 & 4 & 3 \\
3 & 4 & 4 & 3 & 3 & 3,31 & Practical \\
4 & 3 & 3 & 3 & 4 & \\
5 & 4 & 3 & 4 & 3 & \\
6 & 3 & 4 & 3 & 3,67 & \\
7 & 4 & 3 & 3 & 3,67 & \\
8 & 3 & 4 & 4 & 3 & \\
9 & 3 & 4 & 3 & 4 & \\
10 & 4 & 3 & 3 & 3 & \\
11 & 3 & 3 & 3 & 3 & 3 & \\
\hline
\end{tabular}




\begin{tabular}{|c|c|c|c|c|c|c|}
\hline \multirow{2}{*}{ No } & \multicolumn{3}{|c|}{ Observer } & \multirow{2}{*}{ Average } & \multirow{2}{*}{ Overall Average } & \multirow{2}{*}{ Category } \\
\hline & 1 & 2 & 3 & & & \\
\hline 13 & 3 & 3 & 3 & 3 & & \\
\hline 14 & 3 & 3 & 3 & 3 & & \\
\hline 15 & 3 & 3 & 3 & 3 & & \\
\hline 16 & 3 & 3 & 3 & 3 & & \\
\hline 17 & 4 & 4 & 4 & 4 & & \\
\hline 18 & 3 & 3 & 3 & 3 & & \\
\hline
\end{tabular}

\section{Evaluation Phase}

In this phase, evaluation is carried out to find out whether the instrument being developed has been in line with expectations or not. The evaluation was carried out at each ADDIE phase model, and the evaluation was called formative evaluation (Nichols Hess \& Greer, 2016). The purpose of the evaluation in each phase is to measure or determine the success rate of the psychomotor assessment instrument instruments for the competency of the brake system developed.

\subsection{Discussions}

\section{Instrument Validity}

Validity is a criterion that shows the level of validity of an instrument. In addition, validity testing is generally used to measure the extent to which an instrument is capable of carrying out its functions (Shirali, Shekari, \& Angali, 2018). According to Mohamad, Sulaiman, Sern, and Salleh (2015) the instrument can be said to be valid if it can be used to measure what it wants to measure. In this study, the validity test of the instrument was based on the results of the validation of the experts.

In conducting validation, there are at least three aspects of the 11 assessment indicators that must be considered by the validator. The three aspects of the assessment include (1) Material; (2) Construction; and (3) language or culture. Based on the results of the validation test, as shown in Table 1, it is known that the material aspects get a validation value of 4.62 and fall into a very valid category. These results indicate that the instrument developed has conformity to the need for evaluating the psychomotor domain, especially in the braking system competency.

The construction aspect gets a validation value of 4.62 and falls into a very valid category. The validation value shows that the instrument meets the criteria in terms of construction, such as: (1) statements formulated briefly and clearly; (2) statements on the instrument do not have multiple meanings and are irrelevant; and (3) the instrument does not have an uncertain statement. Referring to the explanation above, it can be stated that in terms of the construction of the instrument developed it has conformity to the need for assessing the psychomotor domain, especially in the competence of the brake system.
Language or culture aspects get a validation value of 4.74 and enter into a very valid category. The validation value indicates that the instrument meets the criteria in terms of language or culture, such as: (1) the language used is communicative; (2) instruments using standard Indonesian; and (3) instruments are not taboo languages. Referring to the explanation above, it can be stated that in terms of language or culture, the instrument developed has conformity to the need for evaluating the psychomotor domain, especially in the competence of the brake system. Based on the validation value of three validators that refer to three aspects of assessment, the average validation value is 4.66 and is included in the very valid category. This value indicates that the instrument developed has conformity to the needs of the teacher in conducting an assessment of the psychomotor domain, especially in the competence of the brake system.

\section{Instrument Reliability}

Reliability is the level of consistency of an instrument in measuring what it wants to measure. Another definition was stated by Souza et al., (2017), where it was explained that an instrument was declared reliable if the measurement results were able to show the similarity of the results obtained. Besides, (Scholtes, Terwee, \& Poolman, 2011) explains that instruments that produce a consistent score, relatively unchanged even if used in different situations.

From Table 2, the results of the reliability test above, it is known that the psychomotor domain assessment instrument for brake system competencies gets a reliability coefficient of 0.898 . If the value is adjusted to the classification of Cronbach's Alpha technique category, then it can be stated that the instrument falls into the special category. This shows that the instruments developed are suitable for use and can be trusted.

Based on the test results in Table 3, the inter-observer reliability value is 0.746 . If the results are adjusted to the ICC category classification, then it can be stated that the reliability between observers falls into the medium category. This shows that the three observers reached an agreement regarding the feasibility of the psychomotor domain assessment instrument for the competency of the brake system that had been tested. 


\section{Practicality of Instruments}

Practicality is one of the conditions that cannot be ignored in developing an instrument. Practicality is closely related to the ease of an instrument when used as a measuring instrument (Sumarni, Supardi, \& Widiarti, 2018). There are several things that need to be considered in testing the practicality of an instrument, such as (1) ease when preparing; (2) comfort when using; (3) ease when interpreting or obtaining results; and (4) convenience when storing it (Suparmin, Bakar, Giyoto, \& Fauzi, 2012). According to Dimyati and Mujiono (2006), there are at least five factors that influence the practicality of the instrument. The five factors include (1) ease of administration; (2) the time provided in using the instrument; (3) ease in making judgments; (4) ease in using instruments; and (5) the existence of comparable instruments. In this study, the practicality test results were obtained after the instrument was tested or implemented into the learning process in class XI TKRO 1 in SMKN 1 Jetis Mojokerto.

The practicality test results of the instruments can be seen in Table 4. Based on the data in the Table, the practicality test results are 3.31 in the practical category. The results of the validation show that the psychomotor domain assessment instrument has practicality in its use. Thus it can be concluded that the instrument is feasible if it is used to measure the learning outcomes of students' psychomotor domains.

\section{CONCLUSION}

The results of this development study indicate that the psychomotor domain assessment instrument for the braking system competencies developed is appropriate for use in the learning process. Feasibility is proven from the results of the validation of experts who get an assessment of 4.66 with a very valid category. Then the instrument reliability test results that get the Cronbach's alpha value of 0.895 , and the value of inter-observer reliability is 0.740 . Besides, instruments developed are practical when used in the learning process. This was evidenced by the acquisition of practicality test value of 3.31 and entered in the practical category.

\section{REFERENCES}

Ahmad, A., Kamin, Y., \& Md.Nasir, A. . (2018). Applying Psychomotor Domain for Competency Based Teaching in Vocational Education. Journal of Physics: Conference $\quad$ Series, 012049. https://doi.org/10.1088/1742-6596/1049/1/012049

Ariyanto, S. R., Munoto, M., \& Muhaji, M. (2019). Development of affective authentic assessment instruments for automotive engineering expertise in vocational school. TAMAN VOKASI, 7(1), 42. https://doi.org/10.30738/jtv.v7i1.4777

Begam, A. A. A., \& Tholappan, A. (2018). Psychomotor domain of Bloom's taxonomy in teacher education.
Shanlax International Journal of Education, 6(3), 11-14. https://doi.org/10.1021/am303261c

Branch, R. M. (2009). Instructional Design: The ADDIE Approach. https://doi.org/10.1007/978-0-387-09506-6

Chowdhury, F. (2018). Application of Rubrics in the Classroom: A Vital Tool for Improvement in Assessment, Feedback and Learning. International Education $\quad$ Studies, $\quad 12(1), \quad 61$. https://doi.org/10.5539/ies.v12n1p61

Dimyati, \& Mujiono. (2006). Belajar dan pembelajaran. Jakarta: Rineka Cipta.

Hebebci, M., Kucuk, S., Celik, I., Akturk, A., Sahin, I., \& Eren, F. (2014). Designing an Online Case-Based Library for Technology Integration in Teacher Education. Tojet - The Turkish Online Journal of Educational Technology, 8(8), 1253-1258.

Kasilingam, G., Ramalingam, M., \& Chinnavan, E. (2014). Assessment of learning domains to improve student's learning in higher education. Journal of Young Pharmacists, 6(1), 27-33. https://doi.org/10.5530/jyp.2014.1.5

Lekwa, A. J., Reddy, L. A., Dudek, C. M., \& Hua, A. N. (2019). Assessment of teaching to predict gains in student achievement in urban schools. School Psychology, 34(3), 271-280. https://doi.org/10.1037/spq0000293

Mohamad, M. M., Sulaiman, N. L., Sern, L. C., \& Salleh, K. M. (2015). Measuring the Validity and Reliability of Research Instruments. Procedia - Social and Behavioral Sciences, 204, 164-171. https://doi.org/10.1016/j.sbspro.2015.08.129

Nahadi, Firman, H., \& Yulina, E. (2016). Performance assessment instrument to assess the senior high students' psychomotor for the salt hydrolysis material. 040005. https://doi.org/10.1063/1.4941155

Nichols Hess, A., \& Greer, K. (2016). Designing for Engagement: Using the ADDIE Model to Integrate High-Impact Practices into an Online Information Literacy Course. Comminfolit, 10(2), 264. https://doi.org/10.15760/comminfolit.2016.10.2.27

Scholtes, V. A., Terwee, C. B., \& Poolman, R. W. (2011). What makes a measurement instrument valid and reliable? Injury, 42(3), 236-240. https://doi.org/10.1016/j.injury.2010.11.042

Shirali, G., Shekari, M., \& Angali, K. A. (2018). Assessing Reliability and Validity of an Instrument for Measuring Resilience Safety Culture in Sociotechnical Systems. Safety and Health at Work, 9(3), 296-307. https://doi.org/10.1016/j.shaw.2017.07.010

Souza, A. C. de, Alexandre, N. M. C., Guirardello, E. de B., Souza, A. C. de, Alexandre, N. M. C., \& Guirardello, E. de B. (2017). Psychometric properties in instruments evaluation of reliability and validity. Epidemiologia $e$ Serviços de Saúde, 26(3), 649-659. https://doi.org/10.5123/S1679-49742017000300022

Sumarni, W., Supardi, K. I., \& Widiarti, N. (2018). Development of assessment instruments to measure 
critical thinking skills. IOP Conference Series: Materials Science and Engineering, 349, 012066. https://doi.org/10.1088/1757-899X/349/1/012066

Suparmin, Bakar, U. A., Giyoto, \& Fauzi, A. (2012). Validitas, reliabilitas, dan kepraktisan ujian melalui observasi dan bentuk lisan bagi kelas besar pada prodi PAI Fakultas Tarbiyah dan Bahasa Iain Surakarta. Kodifikasia, 6(1), 65-76. 